\title{
The Effects of Firing Conditions on the Properties of Electrophoretically Deposited Titanium Dioxide Films on Graphite Substrates
}

\author{
Dorian Hanaor, ${ }^{a, *}$ Marco Michelazzi ${ }^{b}$, Jeremy Chenu $^{\mathrm{c}}$, Cristina Leonelli $^{b}$, Charles Sorrell $^{a}$ \\ a: University of New South Wales, School of Materials Science and Engineering, Kensington NSW 2052, Australia \\ b:University of Modena and Reggio Emilia, Department of Materials and Environmental Engineering, 41100 Modena, Italy \\ c: University of New South Wales, School of Chemcial Engineering , Kensington NSW 2052, Australia
}

*Corresponding author, email: dorian@ unsw.edu.au Ph: 61-404-188810

\begin{abstract}
Thick anatase films were fabricated on graphite substrates using a method of anodic aqueous electrophoretic-deposition using oxalic acid as a dispersant. Thick films were subsequently fired in air and in nitrogen at a range of temperatures. The morphology and phase composition were assessed and the photocatalytic performance was examined by the inactivation of Escherichia coli in water. It was found that the transformation of anatase to rutile is enhanced by the presence of a graphite substrate through reduction effects. The use of a nitrogen atmosphere allows higher firing temperatures, results in less cracking of the films and yields superior bactericidal performance in comparison with firing in air. The beneficial effects of a nitrogen firing atmosphere on the photocatalytic performance of the material are likely to be a result of the diffusion of nitrogen and carbon into the $\mathrm{TiO}_{2}$ lattice and the consequent creation of new valence band states.
\end{abstract}

Keywords: Photocatalysis; Films; $\mathrm{TiO}_{2}$; Substrates; Sintering 


\section{Introduction}

The development of novel approaches to water purification is of increasing importance as population growth and climate change place a growing strain on water resources ${ }^{1,2}$. Photocatalysis is an attractive approach to water treatment as this technique does not involve the consumption of chemical reagents, enables the removal of a variety of pollutants, is effective across a wide range of pollutant concentration levels and can be achieved using solar irradiation as the sole energy input ${ }^{3-5}$.

Owing to the distinct levels of its valence and conduction bands, $\mathrm{TiO}_{2}$ has emerged as the leading material in photocatalytic applications ${ }^{6,7} . \mathrm{TiO}_{2}$ photocatalysis takes place through the photogeneration of an electron-hole pair, an exciton, by irradiation exceeding the band gap of the material. This leads to the generation of surface adsorbed radicals and subsequent oxidation of organic pollutants on $\mathrm{TiO}_{2}$ surfaces ${ }^{8}$. The two phases of titanium dioxide most commonly used in photocatalysis are anatase and rutile. Despite the slightly larger band gap of anatase $(\sim 3.2 \mathrm{eV}$ vs. $\sim 3.0 \mathrm{eV})$, this phase is widely considered to exhibit superior photocatalytic activity as a result of greater levels of surface adsorbed radicals ${ }^{9-12}$. It has been frequently reported that mixed-phase $\mathrm{TiO}_{2}$ exhibiting low levels of rutile alongside anatase exhibits enhanced performance through reduced electron-hole recombination ${ }^{13-17}$.

As photocatalyzed destruction of pollutants takes place at close proximity to $\mathrm{TiO}_{2}$ surfaces, a high surface area is advantageous for effective rates of pollutant removal ${ }^{18}$. For this reason studies of water purification by $\mathrm{TiO}_{2}$ photocatalysts are often carried out using aqueous suspensions of powder 19, 20. The disadvantage of using $\mathrm{TiO}_{2}$ in the form of a powder suspended in the treated water is the required catalyst recovery processes, for this reason the immobilisation of $\mathrm{TiO}_{2}$ is frequently carried out $^{21-24}$.

Electrophoretic deposition (EPD) is a practical method for immobilising $\mathrm{TiO}_{2}$ photocatalysts as it enables rapid sample fabrication from suspensions of low solids loading ${ }^{25-27}$. The current work examines the effects of firing conditions on the microstructure and performance of thick films 
prepared by anodic electrophoretic deposition of anatase $\mathrm{TiO}_{2}$ onto graphite substrates. As carbon has been reported to enhance the anatase to rutile phase transformation and lower the band gap in $\mathrm{TiO}_{2}{ }^{28-}$ ${ }^{30}$, this method of fabrication may improve photocatalytic performance by yielding bi-phasic $\mathrm{TiO}_{2}$ at lower temperatures and through carbon doping of the photocatalyst layer.

\section{Experimental Procedure}

\subsection{EPD}

Thick $\mathrm{TiO}_{2}$ films were prepared through anodic EPD from acidic aqueous suspensions adjusted to $\mathrm{pH} \sim 3$ using oxalic acid. As reported elsewhere, the use of oxalic acid imparts a negative zeta potential to $\mathrm{TiO}_{2}$ particles in suspension and thus facilitates anodic EPD from acidic aqueous suspensions with lower levels of water electrolysis ${ }^{31}$. Using a solids loading of $1 \%$, a deposition voltage of $10 \mathrm{~V}$ and a deposition time of $10 \mathrm{~min}, \mathrm{TiO}_{2}$ anatase powder (>99\%, Merck Chemicals) with a BET evaluated surface area of $\sim 10 \mathrm{~m}^{2} \mathrm{~g}^{-1}$, was deposited on $25 \times 25 \times 2 \mathrm{~mm}$ graphite substrates (GrafTech International, Ohio, USA). The average density of 8 thick films prepared was evaluated to be $64.5 \mathrm{gm}^{-2}$ with a standard deviation of $12.2 \mathrm{gm}^{-2}$ and from cross sectional examination the thickness was found to be $\sim 80 \mu \mathrm{m}$.

\subsection{Sintering}

Anatase films deposited on graphite substrates were fired in air using an electric muffle furnace in the range $500-700{ }^{\circ} \mathrm{C}$. Graphite substrates were completely burnt off at $700^{\circ} \mathrm{C}$ when fired in air, while samples fired at lower temperatures exhibited poor adhesion and substrate deterioration. Samples fired in nitrogen were fabricated in a tube furnace at temperatures $500-900{ }^{\circ} \mathrm{C}$ with high purity nitrogen flowing through the tube at $11 \mathrm{~min}^{-1}$. Subsequent to firing, no substrate deterioration was observed in nitrogen fired samples and films showed good adhesion to substrates, although some loosely adhered particles were present. 


\subsection{Microstructural analysis}

Scanning electron microscopy (SEM) and optical microscopy were employed to examine the microstructure of films synthesised in this work. SEM analysis was facilitated using a FEI Nova-230 SEM. Phase identification by laser Raman microspectroscopy was facilitated using a Renishaw inVia Raman microscope with laser excitation at $514 \mathrm{~nm}$ wavelength. Quantitative phase analysis by X-ray Diffraction was carried out using a Phillips MPD unit. Phase fractions were calculated from XRD peaks using the method of Spurr and Myers according to the following equation ${ }^{32}$.

$$
X_{A}=\left(1+1.26 \frac{I_{R}}{I_{A}}\right)^{-1}
$$

In this equation $X_{A}$ is the phase fraction of anatase (assumed $X_{A}=1-X_{R}$ ) and $I_{R}$ and $I_{A}$ are respectively the intensity of the rutile (110) peak at $27.35^{\circ} 2 \theta$ and the anatase (101) peak at $25.18^{\circ} 2 \theta$.

\subsection{Bactericidal Activity}

Bactericidal activity of the samples fabricated in this work was assessed by the inactivation of Escherichia coli (E. coli) AN180 (School of Biotechnology and Biomolecular Sciences, UNSW, Australia) in aerated water, a common approach to evaluating the bactericidal activity of $\mathrm{TiO}_{2}$ photocatalysts. A diagram of the bactericidal reactor is shown in Fig. 1.

Bactericidal evaluation was carried out by adding $2 \mathrm{ml}$ of overnight-incubated $E$. coli culture inTryptone Soy Broth (Oxoid, Basingstoke, UK) to $300 \mathrm{ml}$ of autoclaved distilled water in which photocatalyst samples were placed. The system was irradiated by two $15 \mathrm{~W}$ UV lamps with emission peaks at $\lambda=350 \mathrm{~nm}$. Using a Digitech QM1587 Light Meter, irradiance was evaluated to be $4.42 \mathrm{Wm}$ 1 at the photocatalyst surface. 
The destruction of bacteria was evaluated by determining the concentration of colony forming units (CFUs) in the treated water according to ASTM D5465. $1 \mathrm{ml}$ aliquots of water were taken at fixed time intervals and serially diluted at $1: 9$ ratios in sterile $0.1 \%$ peptone water (Oxoid). Subsequently, $0.1 \mathrm{ml}$ aliquots of the appropriate dilutions were spread-plated on Tryptone Soy Agar (Oxoid) and the plates were incubated for 24 hours at $37^{\circ} \mathrm{C}$. After incubation, colonies were enumerated and counts converted to $\log _{10} \mathrm{CFU} / \mathrm{ml}$, representing the concentration of bacteria in the reactor water.

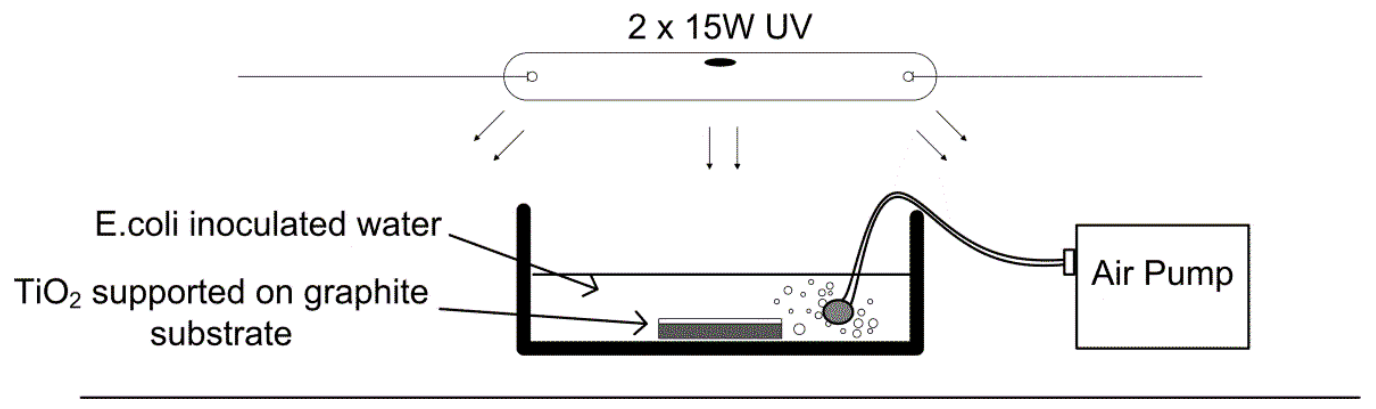

Fig. 1. Diagram of bactericidal reactor

\subsection{Spectroscopy}

The radiative recombination of photogenerated electron-hole pairs in the different samples was studied by examining the intensities of photoluminescence (PL) emission spectra. This was carried out by gathering diffuse spectra in the range $350-900 \mathrm{~nm}(\sim 3.5-1.4 \mathrm{eV})$ using a Kimmon $20 \mathrm{~mW} 325$ nm He-Cd laser in conjunction with a Renishaw inVia Raman microscope.

UV-Visible absorbance spectra were gathered to examine the shift in the absorption edge and overall absorbance between the different samples. These spectra were gathered using a Perkin-Elmer Lambda-35 UV-Vis spectrometer with a Labsphere RSA-PE-20 integrating sphere of $50 \mathrm{~mm}$ diameter. Scans were carried out in the wavelength range $200-700 \mathrm{~nm}$ with a $2 \mathrm{~nm}$ slit width. 


\section{Results}

\section{1. $\quad$ Microstructure}

The prefiring microstructure of all thick films prepared in this work exhibited gas-bubble damage resulting from the parasitic process of water electrolysis as shown in Fig. 2. Holes resulting from bubble damaged ranged from $\sim 5$ to $\sim 50 \mu \mathrm{m}$ in size. Samples fired in air at $700^{\circ} \mathrm{C}$ exhibited complete oxidation of the graphite substrate, leaving behind a fragile unsupported $\mathrm{TiO}_{2}$ film. Samples fired in air at 500 and $600{ }^{\circ} \mathrm{C}$ exhibited substrate deterioration through partial oxidation, resulting in spalling and poor adhesion of deposited films. Samples fired in nitrogen did not exhibit substrate deterioration and resulted in well adhered films showing less cracking as evident from the comparison of Fig. 3a and $3 \mathrm{~b}$. For samples fired at $600^{\circ} \mathrm{C}$ the grain size consisted of anatase grains of $\sim 150 \mathrm{~nm}$ size, increasing with firing temperature, as Shown in Fig. 4. Films fired at $900{ }^{\circ} \mathrm{C}$ showed large $\sim 1 \mu$ coalesced grains of rutile.

Porosity was evident in films fired at all temperatures, a feature likely to be beneficial for photocatalytic applications through the increase in available surface area.

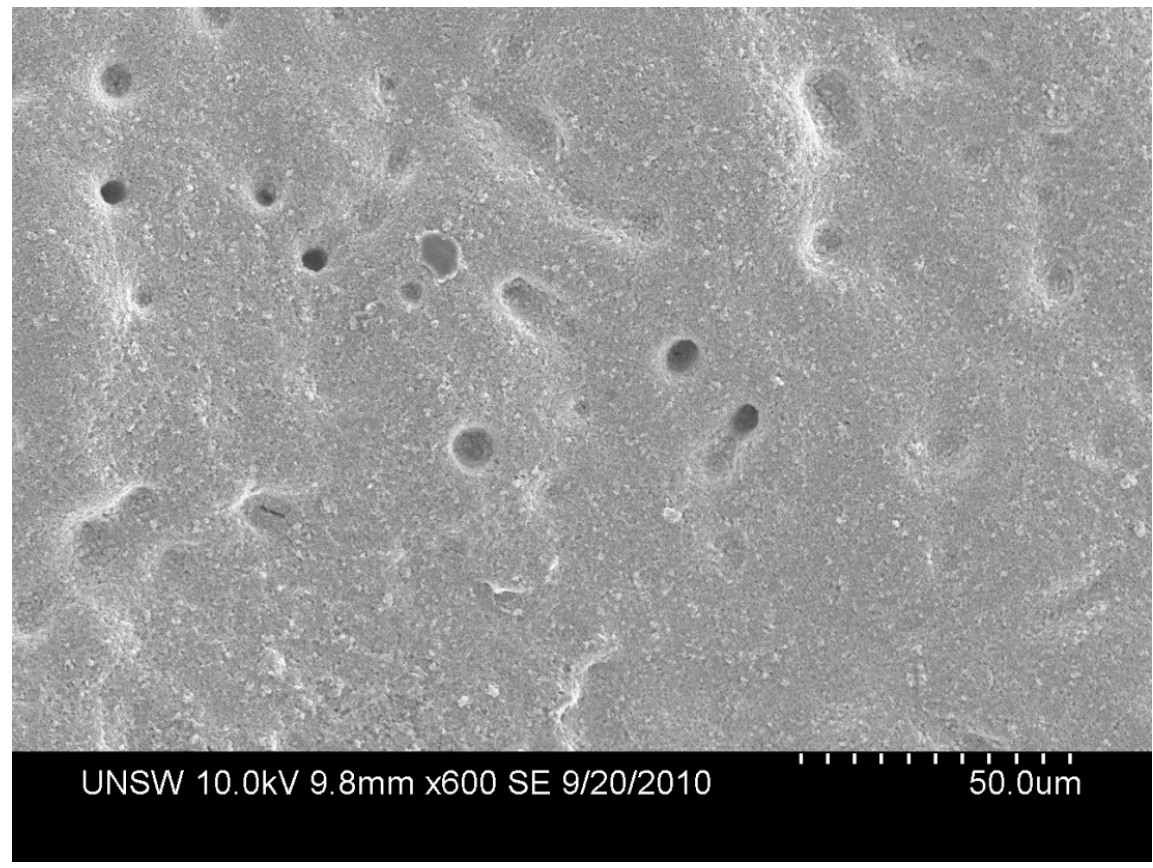

Fig. 2. Typical microstructure showing gas-bubble damage on the surface of a thick film fired in nitrogen at $600^{\circ} \mathrm{C}$. 

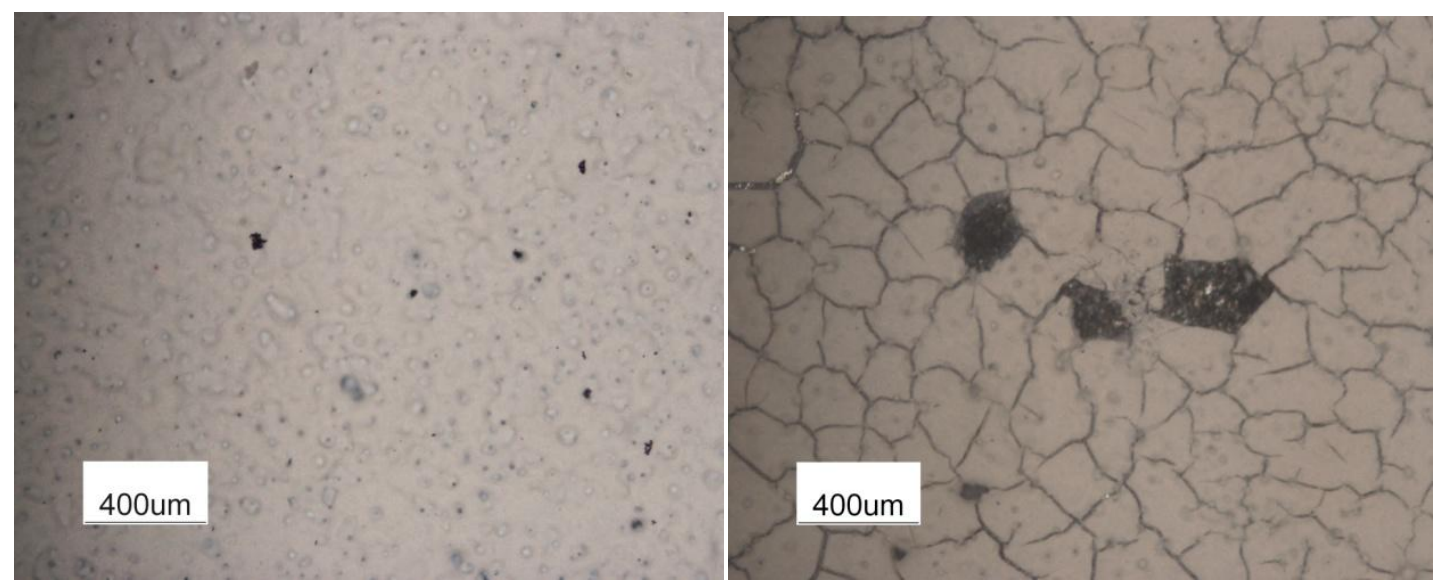

Fig. 3. EPD films fired at $600{ }^{\circ} \mathrm{C}$ (a) in nitrogen (b) in air
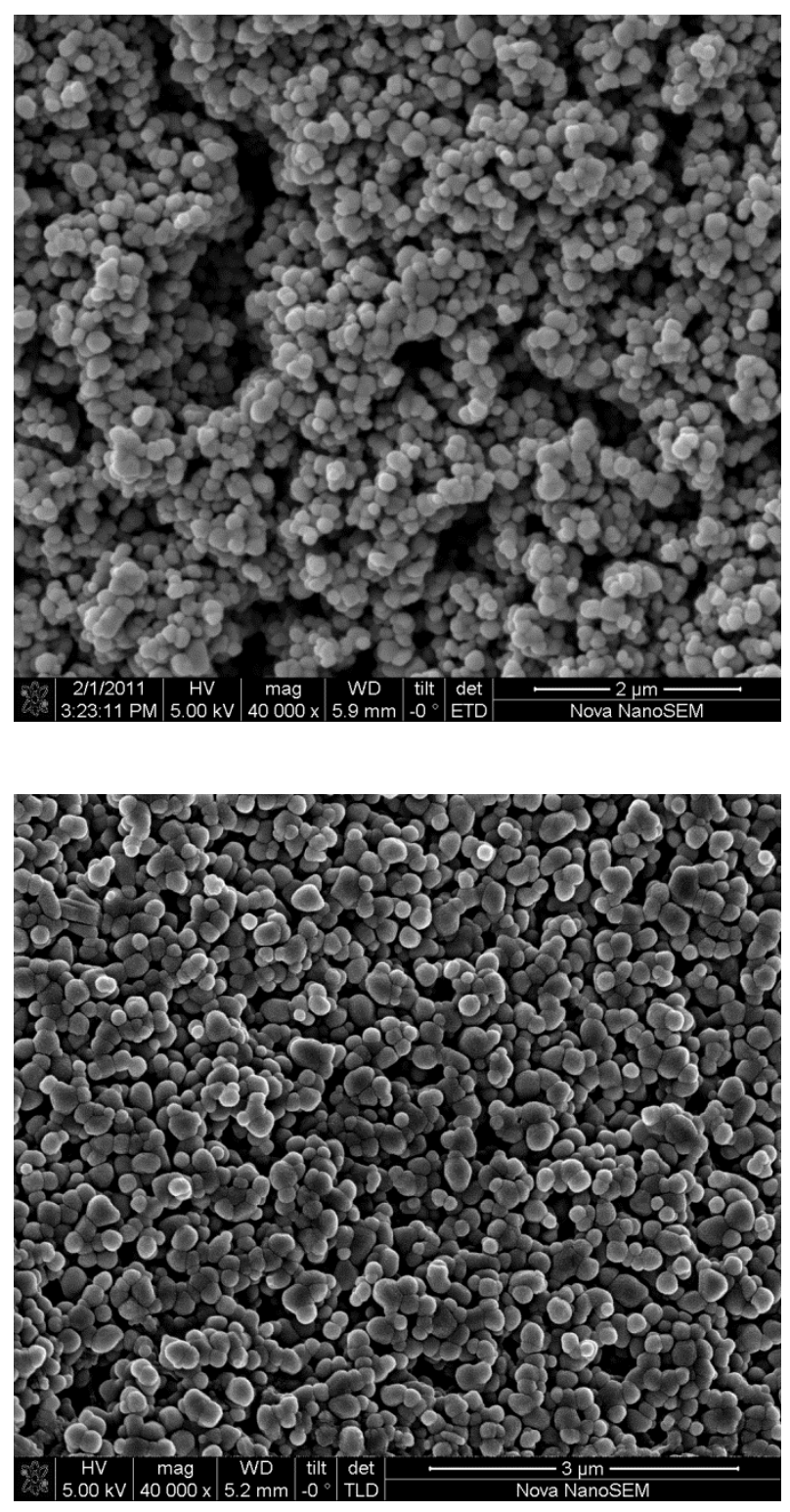


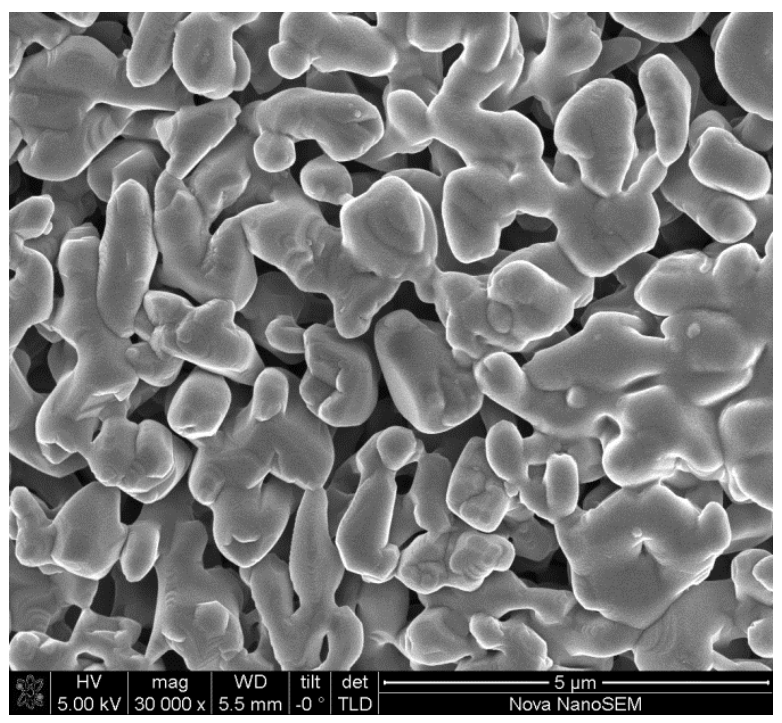

Fig. 4. Microstructure of film fired in nitrogen at (a) $600^{\circ} \mathrm{C}$ (b) $800^{\circ} \mathrm{C}$ and (c) $900^{\circ} \mathrm{C}$

\subsection{Phase composition}

XRD and Raman patterns, shown in Fig. 5. And Fig. 6. respectively, show the presence of rutile in EPD films fired in nitrogen at $800^{\circ} \mathrm{C}$ with near complete transformation to rutile at $900^{\circ} \mathrm{C}$. No significant effect of firing atmosphere on phase transformation was observed as all samples fired in air showed only the anatase phase of $\mathrm{TiO}_{2}$. Unsupported anatase exhibited greater thermal stability and showed only anatase peaks after firing at $800^{\circ} \mathrm{C}$ in air and nitrogen. 


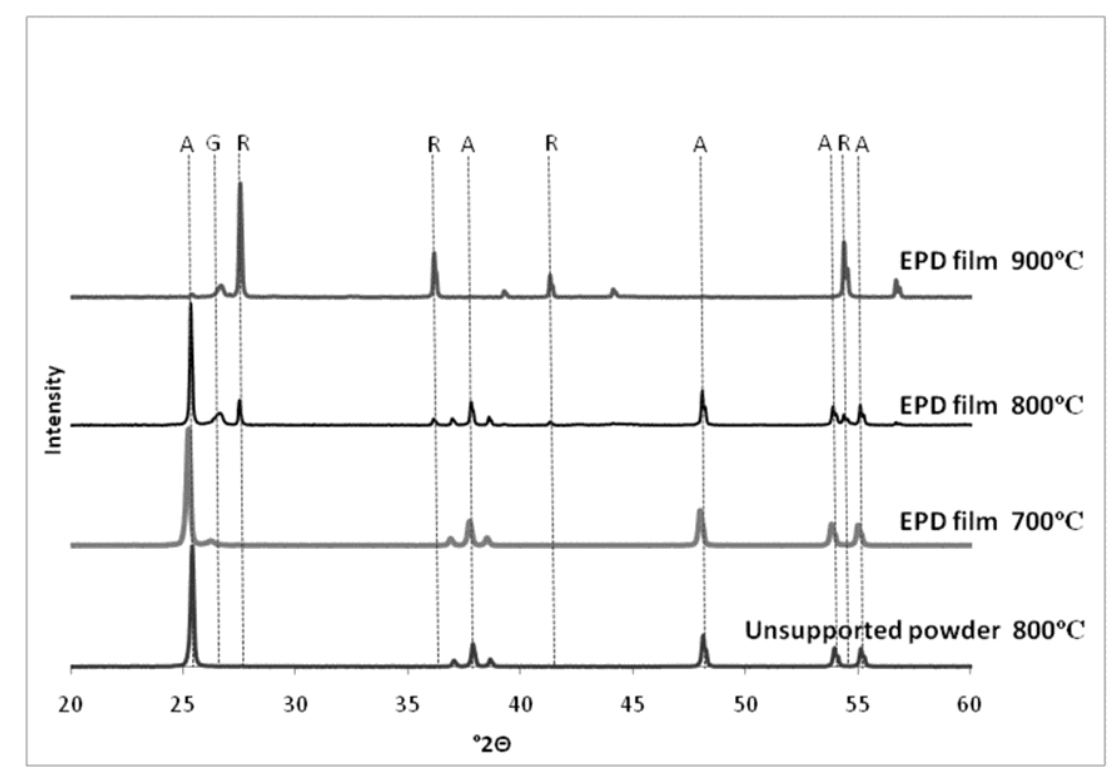

Fig. 5. XRD patterns of samples fired in nitrogen. $A, R$ and $G$ represent anatase, rutile and graphite respectively

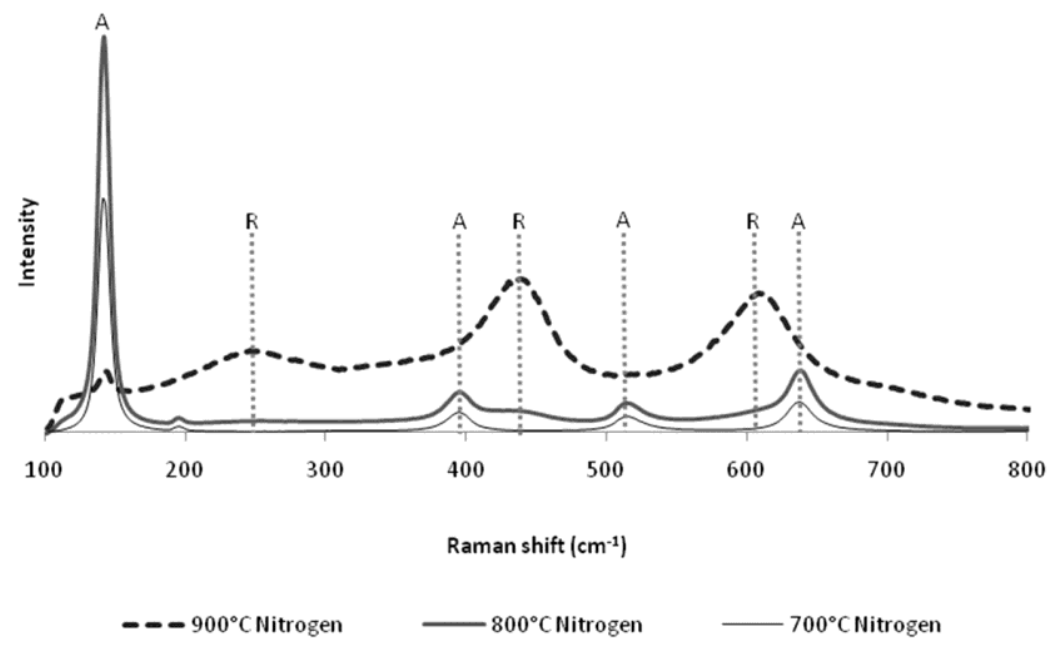

Fig. 6. Raman spectra of EPD films fired in nitrogen with anatase (A) and rutile (R) peaks marked

XRD patterns were interpreted to calculate phase fractions using the method of Spurr and Myers. The quantitative analysis of phase composition is shown in Fig. 7. The enhanced anatase to rutile transformation in graphite-supported thick films is evident from the larger rutile fraction in these samples in comparison with isothermally fired unsupported powder. 
Phase Composition of TiO2 Fired in Nitrogen
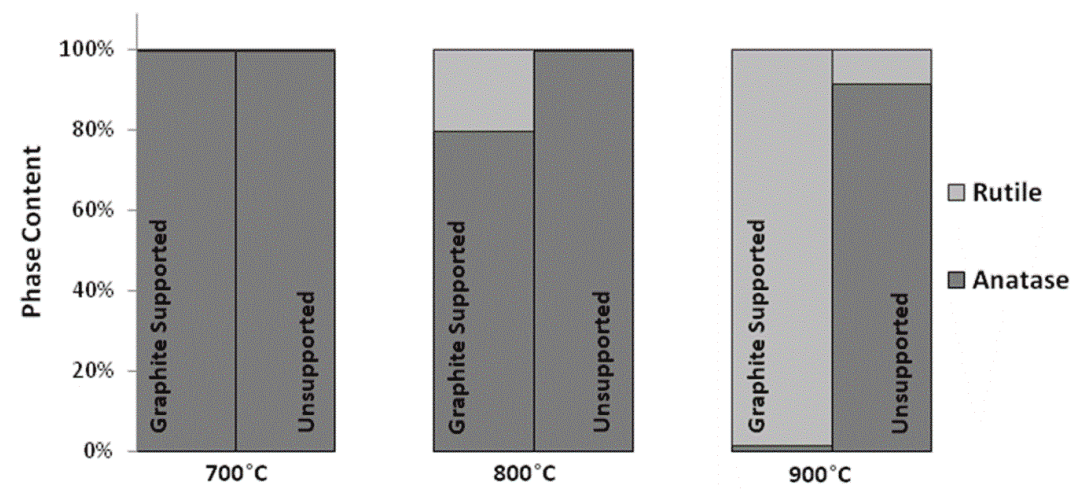

Fig.7. Quantitative analysis of phase composition in graphite supported $\mathrm{TiO}_{2}$ thick films and unsupported $\mathrm{TiO}_{2}$

\subsection{Bactericidal Activity}

The changes in the concentration of $E$. coli AN180 CFUs under UV illumination are shown in Fig. 8. An uncoated graphite substrate was used to evaluate the baseline inactivation of bacteria under UV illumination in the absence of a photocatalyst and it can be seen that only a minor decrease in CFU concentration takes place under such conditions.

Samples fired in nitrogen exhibited superior bactericidal activity than samples fired in air. Nitrogen fired $\mathrm{TiO}_{2}$ thick films facilitated a $>90 \%$ inactivation rate within 20 minutes of UV irradiation while air fired samples did not achieve similar results. The effects of firing temperature on bactericidal activity are not unequivocal from the results, however it appears that sample fired at lower temperature exhibits a higher initial rate of bacteria inactivation.

Complete sterilisation of the water was not achieved within the timeframe of the experiments, rather the microbial concentration reached a sustainable level at which the rate of bacteria inactivation was offset by their natural multiplication. 


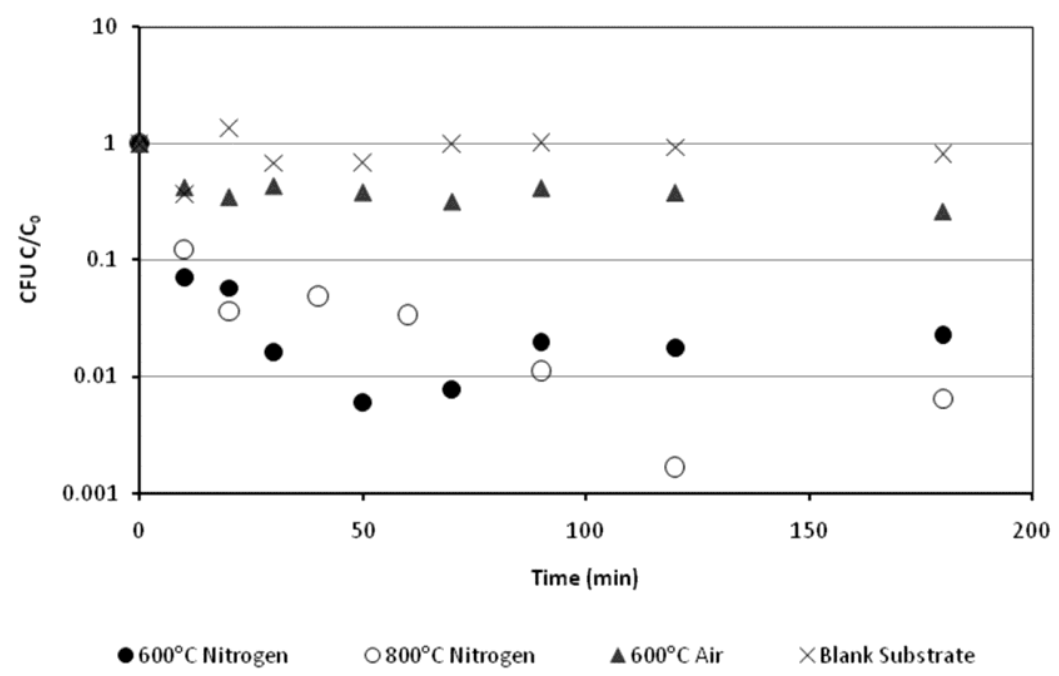

Fig. 8. Concentration of $E$. coli $\mathrm{AN180}$ CFUs as a function of time in bactericidal experiments using $\mathrm{TiO}_{2}$ thick films

\subsection{Spectroscopy}

Photoluminescence emission spectra gathered at room temperature from different films are shown in Fig. 9. The emission peak at $\sim 2.3 \mathrm{eV}$ is consistent with the reported PL spectra of anatase ${ }^{33-35}$. Thick films fired in nitrogen at $600{ }^{\circ} \mathrm{C}$ exhibit higher levels of PL emission which decrease with increasing firing temperature. Consistent with reported data, the decrease in PL emission is particularly significant as the anatase to rutile transformation takes place ${ }^{34,35}$. A sample fired in air exhibited lower PL emission in comparison with sample isothermally fired in nitrogen. This may be a result of lower charge carrier recombination (owing to lower excitation levels or improved electron-hole separation) or a consequence of increased scattering of the $325 \mathrm{~nm}$ UV laser used for photoexcitation. 


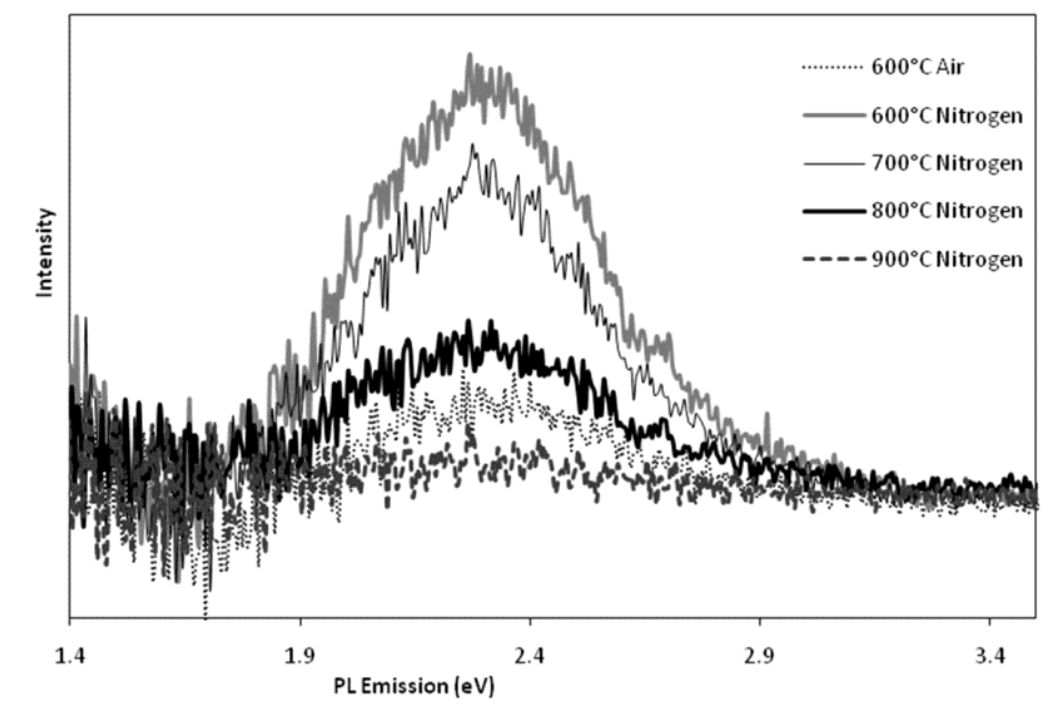

Fig. 9. Photoluminescence emission spectra of samples excited by $325 \mathrm{~nm}$ irradiation

UV-Visible absorption spectra are shown in Fig. 10. An absorption edge at around 380-390 nm corresponds to the band gap of anatase $\mathrm{TiO}_{2}$ of $\sim 3.2 \mathrm{eV}$. It can be observed that samples fired in nitrogen exhibit higher overall absorption and a more moderate slope at the absorption edge. These results cannot be interpreted to determine the photocatalytic performance of the material as increased absorption does not necessarily imply increased photogeneration of electron-hole pairs. Furthermore the differing levels of exposure of the graphite substrates bring about a shift in the absorption levels of the films. The step at $326 \mathrm{~nm}$ is a result of the irradiation lamp changeover at this wavelength. 


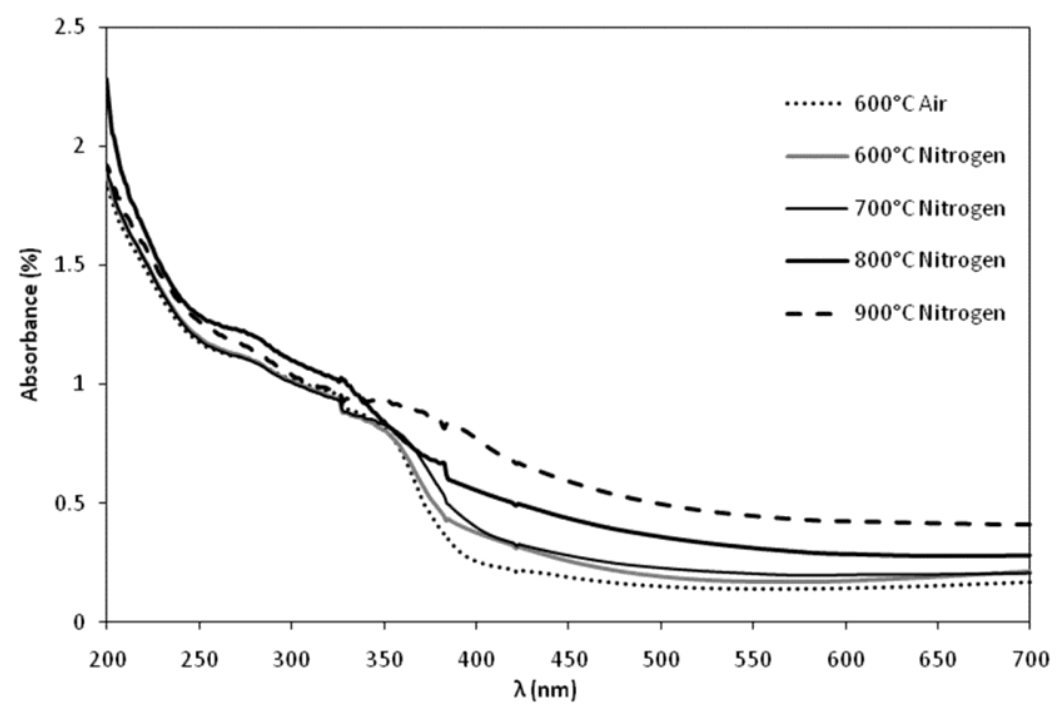

Fig. 10. UV-Visible absorption of $\mathrm{TiO}_{2}$ thick films fired at different temperatures in air and nitrogen

\section{Discussion}

\subsection{Effect of firing conditions on microstructure}

Graphite is generally reported to exhibit rapid oxidation in air around $700{ }^{\circ} \mathrm{C}{ }^{36,37}$ and thus the oxidation of the substrates fired at $700^{\circ} \mathrm{C}$ in air in this work was anticipated. As would be expected, the oxidation of the graphite substrate for films fired in air has a detrimental effect on the structure and adhesion of the deposited thick film. This is evident from increased spalling and cracking, shown in Fig. 3, and the low resilience of the air-fired films to abrasion, suggesting firing in air is an unsuitable treatment for EPD films on graphite substrates, even at temperatures below the ignition temperature of graphite. In contrast, EPD thick films fired in nitrogen did not show oxidation damage and exhibited superior adhesion. As shown in Fig. 4, grain size increased with increasing firing temperature, with a significant growth occurring between $800-900^{\circ} \mathrm{C}$, as the phase transformation to rutile reached near completion. Significant grain growth is likely to be detrimental to the photocatalytic activity of the material due to a decrease in available surface area; however the partial transformation to rutile may be beneficial for the photocatalytic activity through improved charge carrier separation as reported elsewhere. 


\subsection{Phase composition}

The anatase phase of the powder used in this work shows greater thermal stability to what is frequently reported in the literature. While anatase is typically reported to transform to rutile at temperatures between 600 and $700{ }^{\circ} \mathrm{C}{ }^{30,38-41}$, unsupported powder in this work remained entirely in the anatase phase after firing at $800^{\circ} \mathrm{C}$. Similar commercially available anatase has shown thermally stable anatase phase in other work ${ }^{42,43}$, this thermal stability is likely to be due to low levels of silica impurities in the raw material ${ }^{30}$. The presence of the graphite substrate promotes the anatase to rutile transformation. This promotion of the phase transformation, illustrated in Fig. 5. And Fig. 7., is most likely due to the increase in oxygen vacancies in the anatase lattice as reported elsewhere ${ }^{30}$. In a nonoxidising atmosphere, the carbon in the graphite substrate may cause a partial reduction of the $\mathrm{TiO}_{2}$ film giving rise to the formation of oxygen vacancies and $\mathrm{Ti}^{+3}$ species, the presence of which enhances the anatase to rutile phase transformation by easing the atomic rearrangement involved in this transformation ${ }^{44}$.

\subsection{Bactericidal activity}

From Fig. 8. it can be seen that samples fired in nitrogen exhibited superior photocatalytic performance in comparison with air fired material. Higher photocatalytic activity of $\mathrm{TiO}_{2}$ fired in nitrogen has been reported previously ${ }^{45}$. A likely explanation of the enhanced photocatalytic performance observed in samples fired in nitrogen is that this treatment enables the diffusion of nitrogen atoms from the firing atmosphere and carbon atoms from the substrate, into the $\mathrm{TiO}_{2}$ lattice which facilitate an increase in exciton photo-generation. As reported elsewhere $28,29,46$, the substitution of oxygen with nitrogen and carbon atoms in $\mathrm{TiO}_{2}$ gives rise to new valence states and thus increases the optical response by a decrease in the band-gap of the material. It has also been reported that the substitution of carbon and nitrogen in place of oxygen in $\mathrm{TiO}_{2}$ reduces charge carrier recombination ${ }^{28}$. Conversely, in samples fired in air, bactericidal activity was low, showing only moderate activity relative to an uncoated graphite substrate. The lower photocatalytic activity of air 
fired samples may be a result of substrate oxidation which inhibited the diffusion of carbon into the $\mathrm{TiO}_{2}$ lattice and brought about deterioration in the quality of EPD films which resulted in a loss of photocatalyst in the bactericidal reactor.

The effect of increasing firing temperature on the bactericidal activity is not unequivocally clear from the results shown in Fig. 8. It appears the material fired at a lower temperature brings about a more rapid initial bacterial inactivation, however the sample fired at $800^{\circ} \mathrm{C}$ exhibits a lower final $\mathrm{CFU}$ concentration. The differences in bactericidal performance between the two samples fired in nitrogen at different temperatures are not of a significant magnitude, and the ambiguity may result from the mixed effect of grain size and phase composition. The lower-temperature fired material exhibits higher surface area owing to the finer grain size visible in Fig. 4, however the material fired at $800^{\circ} \mathrm{C}$ shows a secondary rutile phase, potentially improving charge carrier separation and consequently improving photocatalytic activity ${ }^{13-17}$. Furthermore the material fired at $800^{\circ} \mathrm{C}$ may exhibit greater levels of carbon and nitrogen diffusion in the $\mathrm{TiO}_{2}$ lattice, giving rise to a lower band-gap.

In general, the bactericidal activity observed in this work was notably low in comparison with results reported elsewhere ${ }^{19,20,47}$, and no complete sterilisation was achieved. The comparatively low rates of E. coli inactivation evident from Fig. 8. are likely to be the result of small catalyst area in comparison with the reactor dimensions, low irradiance levels, the use of air sparging rather than pure oxygen sparging, and the surface area of the commercially available material used which is lower than catalysts used in other work. Irradiance levels in the reactor used in this work were measured at 4.42 $\mathrm{Wm}^{-1}$ while the UV irradiance of sunlight is up to $50 \mathrm{Wm}^{-1}{ }^{48}$. This suggests that greater efficiencies can be achieved using natural solar irradiation rather than illumination by a UV lamp. The deposition of higher surface area $\mathrm{TiO}_{2}$ powder in conjunction with nitrogen firing may yield improved performance than the samples prepared in this work.

\subsection{Spectroscopy}

The photoluminescence spectra of thick films fired in nitrogen shown in Fig.9 exhibit a decrease in PL emission intensity with increasing firing temperature. Increased PL emission in $\mathrm{TiO}_{2}$ results 
generally from increased radiative recombination of excitons ${ }^{49,50}$ and may indicate enhanced photogeneration of these electron-hole pairs, a faster rate of their recombination or a combination of both of these phenomena ${ }^{51-53}$. Intensity of PL emission may also vary as a result of surface properties and resultant variation in the scattering of the photoexciting UV ${ }^{53}$. Consequently, similar to UV-Vis absorbance, PL emission intensity cannot be used to directly infer photocatalytic activity.

The spectra in Fig. 9 show higher levels of PL emission from samples fired in $\mathrm{N}_{2}$ in comparison with a sample fired in air. An increase in PL emission in $\mathrm{TiO}_{2}$ fired in an oxygen deficient atmosphere has been previously reported as a result of increased oxygen vacancies ${ }^{34}$. Additionally, the PL spectra from the sample fired in air at $600{ }^{\circ} \mathrm{C}$ may be diffuse owing to increased surface roughness resulting from oxidation of the substrate and consequent deterioration of the thick $\mathrm{TiO}_{2}$ film.

The similar levels photocatalyzed inactivation of $E$. coli exhibited by samples fired at $600{ }^{\circ} \mathrm{C}$ and 800 ${ }^{\circ} \mathrm{C}$ in nitrogen suggest that the lower PL emission intensity of the sample fired at $800{ }^{\circ} \mathrm{C}$ in nitrogen can be attributed ,at least partly, to improved charge carrier separation in this sample resulting from a mixed anatase-rutile phase composition. If the lower PL emission intensity in the sample fired at 800 ${ }^{\circ} \mathrm{C}$ was purely a result of lower levels of excitation, this material would exhibit markedly poorer photocatalytic activity in the inactivation of bacteria. Conversely if the lower PL emission intensity was solely the result of improved charge carrier separation, this material would be expected to exhibit noticeably higher activity.

UV-Visible spectra shown in Fig. 10 show a more moderate slope at the adsorption edge in nitrogen doped samples with higher overall absorption. These spectra are consistent with the aforementioned formation of new valence states by nitrogen and/or carbon diffusion and the resultant increased optical response ${ }^{54}$. A further increase in overall absorption and broadening of the UV-Vis absorption spectra can be seen as a result of rutile formation. This is consistent with reports that the formation of rutile at low levels is sufficient to shift the absorption edge of $\mathrm{TiO}_{2}$ to higher wavelengths ${ }^{24}$. 


\section{Conclusions}

Porous thick films of $\mathrm{TiO}_{2}$ can be fabricated on graphite substrates by using a method of anodic aqueous EPD. When such fabrication methods are combined with firing in a nitrogen atmosphere a well adhered film exhibiting enhanced photocatalytic activity can be obtained.

The anatase to rutile transformation is enhanced in thick films on graphite substrates as a result of increased levels of oxygen vacancies created by the diffusion of carbon atoms into the $\mathrm{TiO}_{2}$ lattice. The diffusion of carbon and nitrogen into the $\mathrm{TiO}_{2}$ lattice may also explain the improved photocatalytic activity of material fired in nitrogen in comparison with air fired material. A mixed phase composition, achieved by firing at $800^{\circ} \mathrm{C}$ in nitrogen, further enhances photocatalytic activity through improved charge carrier separation.

\section{Acknowledgements}

The authors acknowledge access to the UNSW node of the Australian Microscopy and Microanalysis Research Facility (AMMRF) and the assistance of Anne Rich of the spectroscopy lab at the Mark Wainwright analytical centre at UNSW. 


\section{References}

1. Arnell N. Climate change and global water resources: SRES emissions and socio-economic scenarios. Global Environmental Change. 2004;14(1):31-52.

2. McCullagh C, Robertson JMC, Bahnemann DW, Robertson PKJ. The application of TiO 2 photocatalysis for disinfection of water contaminated with pathogenic micro-organisms: a review. Research on Chemical Intermediates. 2007;33(3):359-375.

3. Dominguez C, Garcia J, Pedraz M, Torres A, Galan M. Photocatalytic oxidation of organic pollutants in water. Catalysis today. 1998;40(1):85-101.

4. Mills A, Davies RH, Worsley D. Water purification by semiconductor photocatalysis. Chemical Society Reviews. 1993;22(6):417-434.

5. Pozzo RL, Baltanas MA, Cassano AE. Supported titanium oxide as photocatalyst in water decontamination: state of the art. Catalysis Today. 1997;39(3):219-231.

6. Daude N, Gout C, Jouanin C. Electronic band structure of titanium dioxide. Physical Review B. 1977;15(6):3229-3235.

7. $\quad$ Fox MA, Dulay MT. Heterogeneous Catalysis. Chem. Rev. 1992;93:341-357.

8. Byrne JA, Eggins BR, Brown NMD, McKinney B, Rouse M. Immobilisation of $\mathrm{TiO}_{2}$ powder for the treatment of polluted water. Applied Catalysis B, Environmental. 1998;17(1-2):25-36.

9. Beltran A, Gracia L, Andres J. Density Functional Theory Study of the Brookite Surfaces and Phase Transitions between Natural Titania Polymorphs. Journal of Phys. Chem. B. 2006;110(46):23417-23423.

10. Mardare D, Tasca M, Delibas M, Rusu GI. On the structural properties and optical transmittance of TiO2 rf sputtered thin films. Applied Surface Science. 2000;156(1-4):200206.

11. Sclafani A, Herrmann JM. Comparison of the photoelectronic and photocatalytic activities of various anatase and rutile forms of titania. Journal of Physical Chemistry. 1996;100:13655 13661.

12. Francisco MSP, Mastelaro VR. Inhibition of the Anatase-Rutile Phase Transformation with Addition of $\mathrm{CeO} \sim 2$ to $\mathrm{CuO}-\mathrm{TiO} \sim 2$ System: Raman Spectroscopy, X-ray Diffraction, and Textural Studies. CHEMISTRY OF MATERIALS. 2002;14(6):2514-2518.

13. Hurum DC, Agrios AG, Gray KA, Rajh T, Thurnauer MC. Explaining the enhanced photocatalytic activity of Degussa P25 mixed-phase $\mathrm{TiO}_{2}$ using EPR. J. Phys. Chem. B. 2003;107(19):4545-4549.

14. Torimoto T, Nakamura N, Ikeda S, Ohtani B. Discrimination of the active crystalline phases in anatase-rutile mixed titanium (iv) oxide photocatalysts through action spectrum analyses. Physical Chemistry Chemical Physics. 2002;4(23):5910-5914.

15. Bacsa RR, Kiwi J. Effect of rutile phase on the photocatalytic properties of nano-crystalline titania. Applied Catalysis B. 1998;16:19-29.

16. Ohno T, Tokieda K, Higashida S, Matsumura M. Synergism between rutile and anatase $\mathrm{TiO} 2$ particles in photocatalytic oxidation of naphtalene. Applied Catalysis A. 2003;244(2):383391.

17. Batzill M, Morales EH, Diebold U. Influence of Nitrogen Doping on the Defect Formation and Surface Properties of $\mathrm{TiO} 2$ Rutile and Anatase. Physical review letters. 2006;96(2):26103.

18. Grzechulska J, Morawski AW. Photocatalytic labyrinth flow reactor with immobilized P25 $\mathrm{TiO} 2$ bed for removal of phenol from water. Applied Catalysis B, Environmental. 2003;46(2):415-419.

19. Cho M, Chung H, Choi W, Yoon J. Linear correlation between inactivation of E. coli and OH radical concentration in TiO2 photocatalytic disinfection. Water research. 2004;38(4):10691077.

20. Maness PC, Smolinski S, Blake DM, Huang Z, Wolfrum EJ, Jacoby WA. Bactericidal activity of photocatalytic $\mathrm{TiO}_{2}$ reaction: toward an understanding of its killing mechanism. Applied and Environmental Microbiology. 1999;65(9):4094. 
21. Balasubramanian G, Dionysiou DD, Suidan MT, Baudin I, Lan JM. Evaluating the activities of immobilized $\mathrm{TiO} 2$ powder films for the photocatalytic degradation of organic contaminants in water. Applied Catalysis B, Environmental. 2004;47(2):73-84.

22. Baram N, Starosvetsky D, Starosvetsky J, Epshtein M, Armon R, Ein-Eli Y. Enhanced photoefficiency of immobilized $\mathrm{TiO} 2$ catalyst via intense anodic bias. Electrochemistry communications. 2007;9(7):1684-1688.

23. Hofstadler K, Bauer R, Novalic S, Heisler G. New reactor design for photocatalytic wastewater treatment with $\mathrm{TiO} 2$ immobilized on fused-silica glass fibers: photomineralization of 4-chlorophenol. Environmental Science \& Technology. 1994;28(4):670-674.

24. Hanaor D, Triani G, Sorrell C. Morphology and photocatalytic activity of highly oriented mixed phase titanium dioxide thin films. Surface and Coatings Technology. 2011;205(12):3658-3664.

25. Besra L, Liu M. A review on fundamentals and applications of electrophoretic deposition (EPD). Progress in Materials Science. 2007;52(1):1-61.

26. Ferrari B, Moreno R. EPD kinetics: A review. Journal of the European Ceramic Society. 2010;30(5):1069-1078.

27. Sarkar P, Nicholson PS. Electrophoretic Deposition (EPD): Mechanisms, Kinetics, and Application to Ceramics. Journal of the American Ceramic Society. 1996;79(8):1987-2002.

28. Yang X, Cao C, Erickson L, Hohn K, Maghirang R, Klabunde K. Synthesis of visible-lightactive TiO2-based photocatalysts by carbon and nitrogen doping. Journal of Catalysis. 2008;260(1):128-133.

29. Wang H, Lewis JP. Second-generation photocatalytic materials: anion-doped $\mathrm{TiO}_{2}$. Journal of Physics, Condensed Matter. 2006;18(2):421-434.

30. Hanaor D, Sorrell C. Review of the anatase to rutile phase transformation. Journal of Materials Science. 2011;46(4):1-20.

31. Hanaor D, Michelazzi M, Veronesi P, Leonelli C, Romagnoli M, Sorrell C. Anodic aqueous electrophoretic deposition of titanium dioxide using carboxylic acids as dispersing agents. Journal of the European Ceramic Society. 2011;31(6):1041-1047.

32. Spurr RA, Myers H. Quantitative Analysis of Anatase-Rutile Mixtures with an X-Ray diffractometer. Analytical Chemistry. 1957;29(5):760 - 762.

33. Tang H, Berger H, Schmid P, Levy F, Burri G. Photoluminescence in $\mathrm{TiO}_{2}$ anatase single crystals. Solid State Communications. 1993;87(9):847-850.

34. Shi J, Chen J, Feng Z, et al. Photoluminescence characteristics of $\mathrm{TiO}_{2}$ and their relationship to the photoassisted reaction of water/methanol mixture. The Journal of Physical Chemistry C. 2007;111(2):693-699.

35. Tang H, Berger H, Schmid P, Levy F. Optical properties of anatase $\left(\mathrm{TiO}_{2}\right)$. Solid State Communications. 1994;92(3):267-271.

36. McKee DW. Metal oxides as catalysts for the oxidation of graphite. Carbon. 1970;8(5):623626.

37. Guo WM, Xiao HN, Zhang GJ. Kinetics and mechanisms of non-isothermal oxidation of graphite in air. Corrosion Science. 2008;50(7):2007-2011.

38. Arbiol J, Cerdא J, Dezanneau G, et al. Effects of $\mathrm{Nb}$ doping on the TiO anatase-to-rutile phase transition. Journal of Applied Physics. 2002;92:853.

39. Ding $\mathrm{XZ}$, Liu $\mathrm{XH}, \mathrm{He} \mathrm{YZ}$. Grain size dependence of anatase-to-rutile structural transformation in gel-derived nanocrystalline titania powders. Journal of Materials Science Letters. 1996;15(20):1789-1791.

40. Okada K, Yamamoto N, Kameshima Y, Yasumori A. Effect of Silica Additive on the Anatse to Rutile Phase Transition. Journal of the American Ceramic Society. 2001;84(7):1591-1596.

41. Vargas S, Arroyo R, Haro E, Rodriguez R. Effect of cationic dopants on the phase transition temperature of titania prepared by the Sol-gel method. J. Mater. Res. 1999;14(10):3932-3937.

42. Kim D, Kim T, Hong K. Low-firing of CuO-doped anatase. Materials Research Bulletin. 1999;34(5):771-781.

43. Dabler A, Feltz A, Jung J, Ludwig W, Kaisersberger E. Characterization of rutile and anatase powders by thermal analysis. Journal of Thermal Analysis and Calorimetry. 1988;33(3):803809. 
44. Shannon RD, Pask JA. Kinetics of the anatase-rutile transformation. Journal of the American Ceramic Society. 1965;48(8):391-398

45. Matsumoto T, Iyi N, Kaneko Y, et al. High visible-light photocatalytic activity of nitrogendoped titania prepared from layered titania/isostearate nanocomposite. Catalysis today. 2007;120(2):226-232.

46. Morikawa T, Asahi R, Ohwaki T, Aoki K, Taga Y. Band-gap narrowing of titanium dioxide by nitrogen doping. JAPANESE JOURNAL OF APPLIED PHYSICS PART 2 LETTERS. 2001;40(6A):561-563.

47. Ireland JC, Klostermann P, Rice EW, Clark RM. Inactivation of Escherichia coli by titanium dioxide photocatalytic oxidation. Applied and Environmental Microbiology. 1993;59(5):1668.

48. Paulescu M, Stefu N, Tulcan-Paulescu E, Calinoiu D, Neculae A, Gravila P. UV solar irradiance from broadband radiation and other meteorological data. Atmospheric Research. 2010;96(1):141-148.

49. Yu PY, Cardona M. Fundamentals of Semiconductors: Physics and Materials Properties. Heidelberg: Springer; 2010.

50. Anpo M, Che M. Applications of photoluminescence techniques to the characterization of solid surfaces in relation to adsorption, catalysis, and photocatalysis. Advances in catalysis. 1999;44:119-257.

51. Yu JC, Yu J, Ho W, Jiang Z, Zhang L. Effects of F-doping on the photocatalytic activity and microstructures of nanocrystalline $\mathrm{TiO}_{2}$ powders. Chem. Mater. 2002;14(9):3808-3816.

52. Anpo M, Aikawa N, Kubokawa Y, Che M, Louis C, Giamello E. Photoluminescence and photocatalytic activity of highly dispersed titanium oxide anchored onto porous Vycor glass. The Journal of Physical Chemistry. 1985;89(23):5017-5021.

53. Lee BY, Park SH, Lee SC, Kang M, Park CH, Choung SJ. Optical properties of Pt-TiO catalyst and photocatalytic activities for benzene decomposition. Korean Journal of Chemical Engineering. 2003;20(5):812-818.

54. Irie $\mathrm{H}$, Watanabe $\mathrm{Y}$, Hashimoto K. Nitrogen-Concentration Dependence on Photocatalytic Activity of $\mathrm{TiO}_{2-\mathrm{x}} \mathrm{N}_{\mathrm{x}}$ Powders. The Journal of Physical Chemistry B. 2003;107(23):54835486. 